\title{
Nascimento do Curso de Psicologia na Metodista - reminiscências dos anos 1971 a 1975
}

\section{The birth of the Psychology Course in Methodist university:History from the years 1971 to 1975}

Péricles de Oliveira Prado Filho*

\section{Resumo}

Em comemoração aos 45 anos do Curso de Graduação em Psicologia da Universidade Metodista de São Paulo, o presente texto tem por objetivo retomar um recorte de sua história, desde seu início em 1972 até 1975, quando de fato o curso se instalou. Para isso, são abordados aspectos da importância da Psicologia como profissão no Brasil, iniciada nos anos de 1960, e traz ainda um pouco da trajetória do autor, que figura entre os primeiros psicólogos brasileiros e que participa e auxilia na instalação da graduação em psicologia nesta universidade. O texto mostra ainda, como a proposta da Universidade Metodista fora inovadora naquela ocasião.

Palavras-chave: Psicologia, História da Psicologia no Brasil; Universidade Metodista

\footnotetext{
* Psicólogo, Mestre em Psicologia Social pela Pontifícia Universidade Católica de São Paulo e licenciado em Filosofia. Professor titular de psicologia social na Universidade Metodista de São Paulo. Foi o primeiro coordenador do curso de psicologia e ocupou cargo de diretor, logo após a consolidação do curso.
} 


\section{Abstract}

In commemoration of the 45th year of the Psychology Undergraduate Program at Methodist University of São Paulo, the present text aims at resuming its history, from its beginning in 1972 until 1975, when in fact the course was installed. To that end, aspects of the importance of Psychology as a profession in Brazil, that began in the 1960s, are discussed, as well as some of the trajectory of the author, who is one of the first Brazilian psychologists to participate in and assist in the installation of a Psychology degree at the university. The text also shows how the Metodista proposal was innovative at that time.

Keywords: Psychology, History of Psychology in Brazil; Methodist University

O objetivo deste texto é o de reavivar algumas lembranças que tenho dos anos iniciais do Curso de Psicologia da atual Universidade Metodista de São Paulo.

A década de 1960 foi muito importante para a formação do Psicólogo no Brasil. Até então os profissionais em Psicologia eram formados em outras áreas, como Filosofia, Pedagogia, Medicina e alguns até sem formação em nível superior. A profissão de Psicólogo foi regulamentada em 1962, e a partir daí, ressalvados os direitos dos que já exerciam a nova profissão, a formação do Psicólogo deveria ser feita exclusivamente em cursos de Psicologia. No início da década de 1970 existiam apenas três cursos de Psicologia em São Paulo: o da Universidade de São Paulo, USP e dois da Pontifícia Universidade Católica de São Paulo - PUC, sendo um na Faculdade São Bento e o outro no Sedes Sapientiae, que já haviam formado alunos como Psicólogos e, no início de 1971 havia sido criada uma Faculdade, com curso de Psicologia, no bairro do Ipiranga.

Em 1970 a Igreja Metodista, fiel a sua tradição educacional, criou o Instituto Metodista de Ensino Superior, que por sua vez propôs ao Conselho Federal de Educação a criação da Faculdade de Ciências Humanas, com os cursos de História, Letras, Pedagogia, Psicologia e Formação de Psicólogos. Os dois primeiros semestres de todos os cursos da nova Faculdade constituíam em um ciclo básico e havia apenas uma matéria específica de Psicologia: Psicologia Geral. As demais matérias eram Filosofia Geral, Sociologia 
Geral, Língua Portuguesa e Língua Inglesa. Dividia as aulas de Psicologia Geral para o primeiro ano básico com outro professor, que coincidentemente era o então Diretor da Faculdade de Teologia, "mãe" da Faculdade de Ciências Humanas. Eram cerca de 500 alunos, divididos em dois turnos, Matutino e Noturno, com turmas de 100 até 130 alunos, misturados nos vários cursos da instituição, já na sua maioria do Curso de Psicologia. Em função do tamanho das turmas, o controle da frequência dos alunos não era feito pelo professor, mas a instituição contratou bedéis para passar a lista de presença, a ser assinada pelos alunos e depois conferida pelo Setor de Aferição. Aliás, uma curiosidade: embora participando das mesmas turmas e tendo aulas com os outros cursos, havia alunos do Curso de Psicologia, matriculados na Licenciatura em Psicologia e alunos do Curso de Psicólogos, matriculados no Curso de Formação de Psicólogos.

Quando fui convidado a dar aulas na Faculdade de Ciências Humanas, além de ser licenciado em Filosofia pela USP, fazia pouco que me havia formado também como licenciado em Psicologia e Psicólogo pela PUC, instituição na qual estava iniciando meu Mestrado, então em Psicologia da Educação, passando para Psicologia Social, quando da criação dessa nova área na PUC. Até então minha atividade principal era de atuar como Psicólogo, pois com o curso de Filosofia já trabalhava ainda antes da regulamentação da nossa profissão na então área de Relações Industriais, especialmente Seleção de Pessoal. Tinha já alguma experiência como professor do ensino médio e do ensino superior, na ocasião lecionando Psicologia Geral e Psicologia Social em um Curso de Ciências Sociais em outra instituição de ensino da região e estava me sentindo mais realizado como professor universitário do que como Psicotécnico e Psicólogo Industrial, que eram os registros mais antigos que tinha em minha Carteira Profissional e atividade profissional que ainda exercia. Curiosamente, a lei que regulamentou a profissão de Psicólogo garantia o meu direito de continuar exercendo a profissão na instituição em que trabalhava, mas não me dava o direito ao registro como Psicólogo, o que foi assegurado apenas àqueles que já contavam com no mínimo cinco anos de exercício nessa função, o que, em 1962, ainda não era o meu caso. 
O Curso de Psicologia da Metodista desempenhou um papel importante na formação de minha identidade pessoal. Afinal de contas participei ativamente do seu processo de formação durante trinta anos de minha vivência profissional, embora já faça quinze anos que do mesmo não mais participo. Desde que saí da Metodista, e mesmo até antes, tenho sido convidado por algumas turmas de ex-alunos para alguns encontros. No inicio deste ano, por exemplo, recebi um convite de um grupo de alunas da primeira turma da Metodista, interessadas em comemorar os quarenta anos de sua formatura como Psicólogas. Participei do encontro com um grupo não muito grande, mas foi emocionante rever aquelas alunas e saber de sua trajetória profissional e pessoal depois de tanto tempo decorrido e de saber que, de alguma forma, participei do seu processo de formação e em alguns casos até interferi no sentido de propiciar condições para determinadas alunas completarem seu curso, sem me dar conta na ocasião que não estava fazendo mais do que minha obrigação profissional.

Isto me fez lembrar com saudades daqueles primeiros momentos quando da criação da Faculdade de Ciências Humanas do Instituto Metodista de Ensino Superior. Participei do primeiro vestibular da Faculdade em um frio sábado de início de inverno do ano de 1971. Já me entrosando com boa parte dos professores da Faculdade, na sua maioria no primeiro semestre dos cursos oriundos da Faculdade de Teologia da Igreja Metodista: Clory, primeiro Diretor da nova Faculdade, Ely Eser, Nilo e reforçados, além de mim, por Beulke e Cleópatra, ficamos até altas horas corrigindo "na unha" as provas aplicadas durante o dia. Na ocasião, não havia computador, eu ainda não tinha carro, morava na Vila Pompéia em São Paulo e cheguei de madrugada em casa, perdendo as festividades juninas que se realizaram em minha rua naquele dia.

O primeiro Diretor Geral do Instituo foi o Dr. Bittencourt. Nosso primeiro Diretor, da Faculdade de Ciências Humanas, foi o prof. Clory, que atualmente aposentado reside em Santa Catarina. Ele e mais os professores Ely Eser e Maraschin davam aulas de Filosofia Geral, dentro do projeto da Faculdade de uma formação humanística. Eu e o professor Nilo dividíamos as aulas de Psicologia Geral, Beulke e Cleópatra davam Sociologia Geral, Gerson e Suzana Lín- 
gua Inglesa e Paulo Damião e José João Cury Língua Portuguesa. O Edifício Alfa, que havia abrigado o Dormitório dos alunos da Faculdade de Teologia, havia sido reformado, sendo construídas quatro grandes salas de aulas nas extremidades tanto do piso inferior quanto do piso superior e foram criadas duas turmas no período matutino e duas turmas no período noturno. O grupo desenvolveu um bom entrosamento e tivemos a possibilidade de trabalharmos juntos no processo de construção e desenvolvimento dos cursos da Faculdade, de um modo especial, no meu caso, o de Psicologia. É de se ressaltar que os professores do primeiro ano, que eram também da Faculdade de Teologia, e que moravam em casas dentro do campus da instituição, e, portanto, mais facilmente acessíveis aos alunos, tinham uma excelente bagagem educacional, com cursos de doutorados e especializações em países como Alemanha, França, Suiça e Estados Unidos.

A população de alunos era muito heterogênea. Como havia até então uma demanda reprimida e o nosso curso de Psicologia foi o primeiro da região tínhamos desde alunos recém-saídos do colegial até senhores e senhoras mais idosos, que não tinham tido oportunidade anteriormente de estudar em nenhum curso superior. Havia alunos de São Paulo, de todas as cidades do ABC paulista e um contingente muito grande de alunos de Santos, pois em tal cidade ainda não tinha nenhum curso de Psicologia. O nome "Metodista", também atraiu muitos candidatos, em função da seriedade que inspirava e pelo bom nome de seu curso de Teologia na região. Como a Faculdade teve seu início em julho de 1971, a decisão da instituição foi a de que houvesse três semestres no período de um ano, e consequentemente a primeira turma não teve férias em dezembro e janeiro, com apenas um breve recesso no Natal e Ano Novo, de tal forma que de julho de 1971 a fevereiro de 1972 foram ministrados os dois primeiros semestres do curso, iniciando-se em março de 1972 o terceiro semestre normalmente. Assim sendo, a primeira turma de Licenciados em Psicologia se formou em 1974 e a primeira turma de Psicólogos em 1975,

Buscando também atender aos anseios dos alunos, já trabalhamos, naquela ocasião, em algumas melhorias do Curso. Inicialmente, já lutando para fazer que não houvesse mais a distinção entre os 
cursos de Psicologia e Psicólogo e buscando no Conselho Federal de Educação a aprovação para um curso único, em que ao final de quatro anos o aluno pudesse formar-se como Licenciado em Psicologia e ao final do quinto como Psicólogo. A proposta pedagógica da nova Faculdade, não era tanto a de formar profissionais específicos, mas sim formar "Humanistas" e, o primeiro currículo do Curso de Psicologia, como os dos demais cursos, contemplava as matérias obrigatórias do currículo mínimo aprovado pelo MEC e uma grande carga horária de disciplinas voltadas para a formação de cidadãos críticos. Ora, embora a proposta fosse bastante avançada, já foi objeto de crítica, por parte dos professores e alunos, pois acabava deixando para um segundo plano a formação profissional específica da área. Nesse contexto, fui convidado pelo Diretor Geral para assumir a chefia do também recém-criado Departamento de Psicologia, e tive como primeira tarefa a de estudar uma proposta para a aprovação de um novo currículo do curso de Psicologia que, sem prejuízo de uma sólida formação humanista, contemplasse essa necessidade de um maior investimento também na formação profissional do Psicólogo.

Um mês após o início do curso, como também minha esposa, então grávida de nossa terceira filha e fazendo parte dessa população represada, iniciara seu curso de Psicologia na Metodista; mudamos então para São Bernardo do Campo, no bairro Rudge Ramos, onde estava, e ainda se encontra, instalada a instituição. É interessante notar que naquele tempo não havia exercício domiciliar para as gestantes, nem bolsa para esposa de professor e, no meio do semestre, às vésperas de um feriado prolongado, tivemos o nascimento de nossa filha, primeira filha da uma aluna da instituição, sem que a mãe deixasse de frequentar às aulas. Além disso, essa nossa filha também se formou em Psicologia, nesse mesmo curso 'onde nasceu' cerca de vinte anos depois.

Fui, então, convidado para trabalhar em tempo integral, quarenta horas semanais, devendo assumir vinte aulas e dedicar as outras vinte para coordenar o projeto de reformulação da grade curricular do Curso de Psicologia. Inicialmente hesitei, pois financeiramente a proposta não era compensadora, uma vez que a remuneração pelas horas dedicadas a tal trabalho era muito inferior a das ho- 
ras em que dava aulas e teria que me afastar de outras atividades profissionais que desenvolvia na ocasião. Depois de alguns dias de reflexão, aceitei o desafio, sendo atraído pela possibilidade de contribuir para o desenvolvimento de um sonho. Assim sendo, o passo seguinte foi trabalharmos no sentido de modificar o currículo do Curso de Psicologia, já para as turmas que estavam cursando o mesmo, aumentando o número de matérias específicas de formação do Psicólogo, uma maior carga horária, e também introduzindo matérias específicas já no primeiro semestre para as turmas novas. Como na ocasião, qualquer alteração dependia de aprovação do Conselho Federal de Educação, buscamos para o primeiro contingente de alunos do Curso, antecipar algumas matérias específicas, previstas para semestres mais adiantados,

Participei ativamente desse processo. Analisei as grades curriculares e entrei em contato com as três Faculdades de Psicologia da cidade de São Paulo, que já tinham formado profissionais em Psicologia, a da USP e as duas da PUC. Examinei também as propostas de duas novas faculdades: uma de Mogi das Cruzes e outra no bairro do Ipiranga,

Neste meio tempo, houve mudança na direção da Faculdade de Ciências Humanas, assumindo como seu Diretor o prof. Luiz Boaventura. Por sua vez, o prof. Ely Eser foi nomeado Vice-Diretor Geral, responsável pela área acadêmica, orientando-nos e aos demais Chefes de Departamento quanto às diretrizes filosóficas e pedagógicas da instituição. Foi contratado um Assessor Pedagógico, Lauro Frederico. Contratou-se também Joel Camacho para coordenar a área de pesquisas da instituição. Com pequena diferença, nascia uma irmã da Faculdade de Ciências Humanas, a Faculdade de Comunicação Social. Começou a desenvolver-se uma sólida contribuição com a área administrativa, com Otoniel Ribeiro. As Secretárias dos Diretores, Alba e Ceila se esmeravam em dar o melhor atendimento possível a alunos e professores. Como na ocasião havia poucos livros disponíveis, tanto nacionais, quanto e especialmente os livros de autores estrangeiros ainda não traduzidos e muito caros criaram-se um Setor de Mimeografia, para onde os professores podiam encaminhar suas apostilas. A Biblioteca da Faculdade de Teologia também passou a atender os alunos da Faculdade de Ciências Humanas, 
sendo ampliado o seu acervo, que embora fosse qualitativamente bom, não teria ainda condições de atender ao crescimento abrupto de alunos da instituição como um todo. Desenvolveu-se um Setor de Multimeios para dar apoio aos professores, principalmente para melhor atender as turmas grandes A partir do terceiro semestre, as turmas também passaram a ser um pouco menores, pois passaram a ser específicas por curso, cerca de sessenta alunos por turma, no caso do curso de Psicologia. Desde o seu início o nosso curso desenvolveu um bom nome, de tal forma que as poucas vagas que surgiam, eram imediatamente preenchidas, ou por alunos de outros cursos da própria instituição, como transferências internas, como alunos já formados em outros cursos superiores, que podiam ingressar sem concurso vestibular, e mesmo alunos de outras novas instituições, que começaram a surgir na cidade de São Paulo e na sua região metropolitana. Houve, inclusive, o caso dos alunos de uma Faculdade da cidade de São Paulo, que por não ter autorização para a formação do Psicólogo vieram em sua totalidade concluir o seu curso na Universidade Metodista.

No processo de reformulação da grade curricular, houve uma permanente preocupação em, ao lado de manter a ênfase humanística, característica da Mantenedora, como entidade confessional, que quanto à formação específica do profissional em Psicologia, esta fosse pluralista e generalista. Havia uma preocupação em que fossem apresentadas aos alunos as várias correntes psicológicas e filosóficas, nas quais elas se baseassem, sem haver uma maior predominância de nenhuma delas. Por outro lado, embora na prática houvesse um maior interesse dos alunos na formação do psicólogo para atuar na Clinica, pretendeu-se também dar uma base sólida para o aluno que aspirasse atuar na Indústria ou na Escola, que eram, na ocasião, as três grandes áreas reconhecidas como de atuação do Psicólogo. Além disso, como para os primeiros alunos era obrigatório que cursassem Licenciatura, preocupou-se também com a formação do professor, embora essa tivesse ficado a cargo dos professores do Curso de Pedagogia. Foi-se montando a infraestrutura do Curso. As primeiras aulas de Fisiologia foram nos laboratórios da Faculdade de Medicina em Santo André, enquanto acompanhávamos os esforços da profa. Neusa, com pleno 
apoio da administração geral, através do Otoniel, para a criação do Laboratório de Fisiologia. O prof. Sérgio, da Universidade de Brasília veio com a proposta do Laboratório de Psicologia Experimental, com o Biotério, propiciando aos nossos alunos os experimentos com ratos albinos. O prof. Agostinho Minicucci, com as aulas práticas de Dinâmica de Grupo, também já respondendo ao anseio dos alunos por mais atividades práticas. As aulas práticas de Psicopatologia foram inicialmente no Hospital Psiquiátrico da Água Funda em São Paulo, lecionadas por Ladislau e Eduardo, enquanto entrávamos em contato com hospitais da região. Luiz Carlos de Neurologia levava seus alunos para conhecer como se dava um atendimento em seu consultório. Enfim, além das aulas em Rudge Ramos, nossos alunos eram itinerantes, com a busca de nossos professores pelos melhores locais para a prática de suas disciplinas. Na medida em que novas turmas iam ingressando, as mais antigas tinham que se deslocar do Edifício Alfa, inicialmente para o Edifício Delta, em construção, e mais tarde também para o Omicron, ainda não concluído. Era comum, pelo menos com os alunos do período matutino o de cruzar com operários com carrinho de mão e ouvir ruídos do processo de construção. $\mathrm{O}$ interessante é que tudo isso era visto com boa vontade pela quase totalidade dos alunos e professores, que até mesmo se orgulhavam de participar desse processo de construção. Havia improvisação até em uma cantina para um rápido cafezinho. A atual Praça Central do campus Rudge Ramos, que havia sido um campo de futebol da Faculdade de Teologia era usada como estacionamento para professores e alunos, transformando-se em um lamaçal nos dias de chuva. Um episódio interessante a relatar é que, quando ainda em construção o Edifício Delta os alunos do curso de Psicologia já tinham aulas em salas semi-construídas do mesmo. Em uma noite de aulas, um professor do curso estava aplicando uma prova quando, pouco antes do término previsto para a mesma, quando a maior dos alunos já havia entregado a sua prova faltou energia elétrica na instituição. $\mathrm{O}$ professor não teve dúvidas: fez os poucos alunos que ainda não haviam terminada a prova pegarem suas carteiras e levá-las para frente do edifício Delta no estacionamento e solicitou a alguns alunos que já a haviam terminado 
que acendessem os faróis dos seus carros iluminando as carteiras dos retardatários, e assim todos concluíram suas provas, mesmo naquelas circunstâncias.

Pouco a pouco foram chegando os novos professores do Curso de Psicologia e consequentemente ampliando a participação do grupo e ajudando em uma nova reformulação do curso para as novas turmas. João Augusto em Psicologia Geral e Teorias e Sistemas, Marilda Danna, Maria Emília e Benê em Psicologia Experimental, Eda Marconi, Vera Lúcia, Alvino Sá, Célia, Silvia e Lídia, esta última, inicialmente como Auxiliar de Ensino, em TEP e Virginia, comigo em Psicologia Social, Anita Neri e Berta em Psicologia do Desenvolvimento, Belisário em Teorias e Sistemas, Ladislau e Eduardo em Psicopatologia, Maria Helena Berkers em Psicologia Geral e Psicologia da Personalidade, Luiz Carlos em Neurologia, Antonio Carlos Gil, comigo em Metodologia de Pesquisa Psicológica, Valderi em Metodologia Científica, Vladimir em Estatística, Maria Tereza e Maria Beatriz em Dinâmica de Grupo, Iara e Geraldo em Antropologia Cultural, Geraldino em Psicologia da Personalidade e Teorias e Técnicas Psicoterápicas, Ana Maria Lanzoni em TTP, Johannes Berkers em Técnicas de Aconselhamento Psicológico e Ética Profissional, Vera Regina e Ana Maria Pires em Psicologia do Excepcional, Maria Luiza, Glória Elisa e Jane em Psicologia do Escolar, Sigmar Malvezi, Maria Olívia, Maria Cecília, Agnaldo Neri, em Psicologia da Indústria, Osmar em Educação Física. Como estou recorrendo à memória, sem acesso aos documentos da ocasião, é possível que esteja omitindo alguém. Mas, o que estou querendo destacar é que, nos seus cinco primeiros anos de curso, o Departamento de Psicologia atuou de uma forma ativa, e com a colaboração decisiva de seus professores, não só aprovando as alterações da grade curricular do curso, mas inclusive, em reuniões bastante concorridas e participativas, algumas até mesmo sem remuneração específica, eram discutidas e aprovadas, com participação também do prof. Ely, representando a Mantenedora, os programas das disciplinas e mesmo a aprovação dos novos professores do Departamento.

Fazíamos muitas reuniões com a totalidade dos professores do Departamento. Lembro-me inclusive de uma reunião em um sábado de 1974 em que na Copa do Mundo de Futebol, a seleção 
brasileira disputava um jogo decisivo da fase de classificação com a seleção do então Zaire e nós reunidos, alguns com o ouvido no radinho de pilha ou mesmo em uma televisão daquele tempo que tinha na cantina... Além disso, como morávamos perto da Faculdade era comum recebermos professores e mesmo alunos em casa para discutirmos problemas do Curso.

Quando da criação da Faculdade de Comunicação Social, houve uma boa integração com os professores da nova faculdade, especialmente com o prof. Brose, que também era professor da Faculdade de Teologia, e junto com o então Coordenador Administrativo, Otoniel, davam todas as condições de infraestrutura, para a criação de pequenos filmes, como por exemplo, simulando aplicação de testes, experimentos da disciplina Psicologia Experimental. Eu mesmo tive a oportunidade de filmar a reprodução de experimentos em Psicologia Social, como o de conformismo de Salomon Asch, com a participação dos alunos e colaboração efetiva das áreas de Comunicação e Administrativa. No processo de integração com a Faculdade de Teologia demos aulas de Psicologia Social a alunos daquela Faculdade, alguns até futuros bispos da Igreja Metodista, na mesma turma que os alunos de Psicologia. Na ocasião, inclusive, participamos da Congregação da Faculdade de Teologia.

As atividades práticas do curso de Psicologia se iniciaram em duas casas da Rua do Sacramento, pertencentes à Faculdade de Teologia, e que atualmente servem de residência a alunos da referida Faculdade, com a realização de treinamento de monitores de Psicologia Social e TEP e atividades práticas em TEP. Ao final do curso a administração da instituição designou o Edifício Alfa para o Setor de Psicologia Aplicada, com sua Clínica Psicológica, salas de supervisão de todas as áreas de estágio e atividades práticas do curso, e foi apresentado um projeto de reforma do mesmo, sendo os nossos pedidos prontamente atendidos pela área administrativa.

Antes de falar no processo de montagem do quinto ano, gostaria de comentar quanto a participação dos alunos do curso. Embora, como já mencionei, a população fosse muito heterogênea, os nossos alunos, desde o primeiro ano, eram críticos e participativos. Inicialmente, trazendo as suas reivindicações e revelando seus anseios e aspirações, que tínhamos que levar em conta no processo de cons- 
trução do curso. Além disso, já no segundo semestre do Curso pudemos contar com alguns alunos, especialmente do período matutino, que, já aprovados em Psicologia Geral I e com bom desempenho em Psicologia Geral II, passaram a atuar como Monitores, com nossa supervisão, para os alunos que ingressaram no início do ano de 1972, nas segundas turmas do curso. Quando começaram disciplinas mais técnicas, como TEP, por exemplo, criamos uma figura, que por falta de melhor nome, chamamos de "Auxiliar de Classe", em que alunos da própria turma eram previamente treinados para auxiliar o professor nas atividades práticas dos seus próprios colegas. Não vou mencionar nomes, pois aqui a possibilidade de eu cometer injustiças e esquecer alguns nomes é grande, pois foram dezenas de alunos que se envolveram nesse projeto. De qualquer forma, não posso deixar de mencionar que, logo muitos desses alunos passaram a ser Monitores das turmas seguintes, e mais tarde se tornaram auxiliares de ensino e professores de nossa e de outras instituições, fazendo carreira universitária. É interessante notar que, embora vivêssemos em pleno período de ditadura militar e repressão, havia uma preocupação em desenvolver um ambiente democrático entre os alunos. Assim sendo, houve pleno apoio da instituição à criação dos Diretórios Acadêmicos por parte dos alunos, inclusive atribuindo-se locais dentro do campus para as sedes dos mesmos. Foi significativo também que, quando nossos alunos se preocuparam em nomeá-los as personalidades escolhidas foram os indigenistas irmãos Villas-Boas, tendo o Diretório Acadêmico da Faculdade de Ciências Humanas sido batizado como D.A. Orlando Villas-Boas e o de Comunicação Social como D.A. Cláudio Villas-Boas.

Sempre houve também uma preocupação com um entrosamento com a comunidade, mesmo antes da implantação do quinto ano. Buscavam-se contatos com órgãos públicos, tanto do município quanto do estado ou federal. Os alunos foram incentivados desde o início do curso a participar de projetos, como o Projeto Rondon, que levava alunos de vários cursos para desenvolver atividades relativas à sua formação profissional em municípios carentes do país. Finalmente, iniciou-se o quinto ano, com o predomínio das atividades de estágio. De um modo especial Vera Lúcia Wey trabalhou na montagem da estrutura do Setor de Psicologia Aplicada com três 
grandes áreas: Clínica Psicológica, Psicologia Aplicada à Educação e Psicologia Aplicada à Indústria. Com a participação de alguns professores do curso, e com um novo contingente de Psicólogos, montaram-se os grupos de supervisão e iniciou-se um novo desafio para a complementação da formação dos Psicólogos das primeiras turmas da Faculdade de Ciências Humanas do Instituto Metodista de Ensino Superior. Assumiu a chefia do Setor o prof. Johannes. Foram contratados Assessores da Chefia, psicólogos recém-formados, Beatriz, Yolanda, Mirtes, José Paulo Fonseca, para montar toda a infraestrutura de atendimento, tanto na parte burocrática, com a elaboração do material e impressos necessários, bem como a busca de clientes para as três áreas do Setor, a Clínica Psicológica, a Psicologia Aplicada à Educação e a Psicologia Aplicada à Indústria. Cabe ressaltar que o Assessor designado para a área de Indústria, fez um trabalho tão bom, que foi contratado como Psicólogo de uma das grandes empresas da região que contatou, além do fato de outras duas, que eram professoras primárias, foram convocadas para trabalhar no Departamento de Assistência ao Escolar do Estado de São Paulo, o que propiciou grande abertura para os nossos alunos estagiarem na área de Psicologia Aplicada à Educação nas escolas estaduais. Lembramos ainda que, nos vários anos seguintes, nosso Setor de Psicologia Aplicada foi uma referência de qualidade e recebemos muitos psicólogos de outras instituições, não só da região, mas mesmo de outros estados do Brasil, buscando se beneficiar de nossa experiência.

Em 1975 houve uma reformulação na estrutura da Faculdade e dos cursos: o prof. Ely Eser foi nomeado Diretor da Faculdade de Ciências Humanas, Para cada curso foi indicado um Coordenador, cabendo a mim a incumbência de ser o primeiro Coordenador do Curso de Psicologia. Criaram-se dois departamentos para as matérias específicas do Curso, sendo nomeados os professores Alvino para o Departamento de Clínica e Fundamentos Psicológicos e Sigmar para o Departamento de Psicologia Social, Escolar e do Trabalho. É interessante notar que, por razões administrativas, inclusive financeiras, os estágios e suas respectivas supervisões não estavam ligados ao Departamento, mas ao Setor de Psicologia Aplicada, que na prática acabou se constituindo em um terceiro Departamento. Os superviso- 
res de estágio foram inicialmente contratados como Psicólogos e não como Professores, inclusive com um valor um pouco inferior ao da hora-aula. A primeira grande reivindicação acabou sendo a de igualar os salários, o que se conseguiu com pouco tempo. A integração formal com os Departamentos somente foi feita alguns anos depois, embora, na prática, os professores dos Departamentos e os Supervisores de Estágio, sendo que muitos professores eram também supervisores, houvesse integração nas reuniões de professores do Curso.

Também desde o início do curso houve a preocupação de integração com o também incipiente Conselho Regional de Psicologia, bem como a realização de Semanas Culturais, com a participação não só dos professores da casa, mas buscando atrair profissionais atuantes de outras instituições. Uma curiosidade: em uma das muitas programações culturais da Faculdade foi convidado o historiador Sérgio Buarque de Holanda para ministrar uma palestra. A divulgação do seu nome causou um frenesi entre os alunos. No dia em que ele compareceu o Salão Nobre estava superlotado. Provavelmente, a expectativa dos alunos é que viesse acompanhado de seu já famoso filho, Chico Buarque. Mas, fato tragicômico: ele iniciou sua palestra e o salão foi progressivamente esvaziando, de tal forma que ao final de sua conferência havia pouquíssimos alunos presentes...

Para encerrar gostaria de enfatizar que, dos meus cinquenta anos de vida profissional ativa (1955 a 2004), passando por várias atividades e várias instituições, os anos de 1971 a 1975 representam para mim um período dos mais marcantes, pois tive a oportunidade de contribuir com paixão, juntamente com um grupo de professores idealistas, tanto psicólogos como profissionais de outras áreas, e contando com alunos interessados e participativos, para o início do processo da formação da identidade do nosso curso de Psicologia.

Contato do autor:

Péricles O. Prado Filho

Email: periclesfilho@uol.com.br

Recebido em: 02/09/2015

Aceito em: 12/12/2015 